\title{
Resurrección: apuntes entre cristología y apocalíptica*
}

Mario Alejandro Arias J.**

\section{Resumen}

El artículo es una aproximación al tema de la Resurrección desde la perspectiva cristológica y la apocalíptica. La base para este escrito se encuentra en el pensamiento de Wolfhart Pannenberg, y algunas conclusiones sobre el problema de la muerte y resurrección de Jesús. El punto de partida es una reflexión sobre los horizontes procesuales de la Cristología, para poder situar al teólogo Pannenberg, del que se expone la crítica a que se ve sometido y los puntos que él mismo define a su favor. El punto segundo hace una revisión sintética de lo que es el binomio Muerte-Resurrección en la amplitud de la literatura apócrifa, los fundamentos histórico-literarios y la diversidad de perspectivas y esquemas que identificaban a la comunidad primitiva para hacer lectura de su evento fundante; $y$, en un tercer punto, los elementos de la apocalíptica como género apropiado para la experiencia y la comunicación del Kerygma.

\footnotetext{
El autor invita a leer su texto como un artículo de reflexión. Su intención no radica en profundizar lo dicho por grandes teólogos de la escatología, sino en escudriñar fuentes en las que se pueda establecer un trasegar del tema de la Resurrección. No pretende ser exhaustivo sino, más bien, observador de un proceso que tiene diversas aristas y modos diversos-seguramente más cualificados- de aproximación. Reflejo de ello es el término Apuntes usado en el título del artículo. Igualmente, este texto es resultado del proyecto de investigación "Wolfhart Pannenberg: la pretensión de verdad de la esperanza cristiana", realizado en la Universidad de San Buenaventura, Bogotá, 2010-2011.

** Presbítero diocesano de la Arquidiócesis de Medellín, teólogo de la Universidad Pontificia Bolivariana, con especialización bíblica en el Studium Biblicum Franciscanum de Jerusalén. Ha ejercido su labor teológico-docente en distintos centros de formación académica: la misma Universidad Pontificia Bolivariana, la Fundación Universitaria Luis Amigó, en Medellín; pero también en seminarios diocesanos, con una labor académica y formativa en el Seminario Mayor de Medellín y Seminario Juan Pablo II en la misma ciudad, en La Habana (Cuba) y en Cúcuta (Norte de Santander). Actualmente es docente de la Facultad de Teología de Universidad San Buenaventura, Bogotá, y docente en la Maestría en Teología de la Biblia en la misma universidad. Contacto: marias@usbbog.edu.co.
} 


\title{
Palabras clave
}

La tercera cuestión, resurrección, Pannenberg, cristología, apocalíptica.

\section{Resurrection: some notes between Christology and Apocalyptic}

\begin{abstract}
This article is an approach to the resurrection from the Christological and the apocalyptic perspective. The basis for this paper lies in the thought of Wolfhart Pannenberg, and some conclusions on the problem of death and resurrection of Jesus. The starting point is a reflection on procedural horizons of Christology, for it to place the theologian Pannenberg, who outlines the criticism to which it is subjected and the points defined by him in his own favor. The second point is a review summary of what the binomial Death-Resurrection is in the amplitude of the apocryphal literature, literary and historical fundamentals and the diversity of perspectives and schemes that identified the first community to read their founding event; and in a third point, the elements of the apocalyptic as an appropriate genre to the experience and communication of Kerygma.
\end{abstract}

\section{Keywords}

The third question, Resurrection, Pannenberg, Christology, Apocalyptic.

\section{Aspectos del proceso de la cristología}

Nuestro primer esfuerzo se acerca a la realidad de la cristología, con los presupuestos que conocemos hoy, de tal manera que podamos tener a la mano las herramientas que nos permitan decir algo sobre 
la cristología en la especificidad de la Resurrección, dialogando con algunas ideas de Wolhart Pannenberg, teniendo como punto de partida un artículo de su obra "Fundamentos de Cristología" y observando algunos planteamientos sugeridos por el mismo autor en un segmento de su obra "Teología Sistemática"1.

Se intenta, en lo que sigue, hacer una aproximación diagnóstica actualizada al estudio del Jesús histórico ${ }^{2}$. Esto con el fin de poder situar a Pannenberg, y situarnos nosotros, en esa misma búsqueda que ha caracterizado el objeto de la cristología en años recientes.

1. La aproximación al Jesús histórico cuenta con tres búsquedas en los dos últimos siglos: la "Antigua búsqueda" (Old quest- s. XIX), la "Nueva búsqueda"3 (entre 1950-1980) y la "Tercera búsqueda" (desde 1980 hasta hoy) ${ }^{4}$. Aclárese que por "Jesús histórico" no se entiende el Jesús real ni el Jesús terreno; es el Jesús que se puede recuperar utilizando los recursos y la metodología de la investigación histórica, tratándose de una reconstrucción limitada y perfectible. Así es todo conocimiento histórico.

2. En ese esquema clásico de las búsquedas, no se tienen en cuenta los primeros 50 años del siglo $\mathrm{xx}$, donde hubo un profundo escepticismo respecto a acceder a Jesús históricamente. Además, la distinción entre las dos últimas búsquedas se debe al gran desarrollo de los estudios sobre Jesús en los últimos veinte años. Guijarro Oporto, prefiere situar etapas más amplias caracteriza-

1 Wolfhart Pannenberg, Fundamentos de cristología (Salamanca: Sígueme, 1974), 67-142; “La divinidad de Jesucristo", en Teología Sistemática, Vol. II. (Madrid: UPCO, 1996), 351-426.

2 Retomamos los aportes de Álvaro Cadavid, "La investigación sobre la vida de Jesús", Teología y Vida 4, Vol. xuII (2002): 512-540. www.scielo.cl/scielo.php?pid=S0049-34492002000400003\&script=sci_ arttext; Santiago Guijarro Oporto, Jesús y el comienzo de los Evangelios (Navarra: Verbo Divino, 2006), 19-21; Rafael Aguirre, "La «Third Quest» ¿̇Una nueva investigación?", RCatT 2, Vol. xxxiII (2008): 301-325.

3 La «nueva búsqueda» dejó aportes interesantes: sirviéndose de la historia de las formas, de la redacción y de los criterios de autenticidad histórica, se superó la división que se había hecho entre comunidad pre y pospascual, y se visualizó a los evangelistas con un papel teológico en la composición de los escritos evangélicos. Además, el Jesús histórico y el Cristo de la fe, recuperaron su unidad; el acontecimiento y la interpretación, la historia y la fe, tuvieron la misma suerte. Álvaro Cadavid, op. cit., 525.

Un recorrido esquemático y definido de las tres búsquedas, en Ídem. 
das por su escepticismo: finales del xviII y todo el s. XIx; la primera mitad del xx; la segunda mitad del s. xx en adelante.

3. Según la clasificación anterior, la fase iniciada hacia $1980^{5}$, fue impulsada por factores como: la aparición de nuevas metodologías para la mejor comprensión de los textos neotestamentarios, con la ayuda de las ciencias sociales. Las nuevas metodologías coincidieron con un mejor conocimiento de los textos canónicos, apócrifos, las obras de Flavio Josefo, los escritos de Qumram, y los aportes arqueológicos ${ }^{6}$. De todo esto, emerge un conocimiento más preciso del contexto socio-religioso decisivo para esta fase.

4. La investigación bíblica, en consecuencia, dejó de ser patrimonio de la teología alemana, fundamentalmente protestante, y tomó lugar en Norteamérica, integrándose disciplinas nuevas (antropología o arqueología), otras confesiones o religiones (católicos y judíos), con nuevos horizontes (más interdisciplinar, interreligiosa e internacional).

Posiblemente, en este sentido, se ha hecho interesante y a la vez polémico, el grupo de estudiosos norteamericanos denominado Jesus Seminar. Según N. T Wright, el problema radica en el hecho que, ciertos movimientos investigativos han traído de nuevo aspectos que ya habían sido superados en el trasegar de la investigación cristológica, por ejemplo, volver a la desconfianza sobre el valor histórico de los evangelios canónicos y la posterior «desescatologización» de Jesús es retornar a los presupuestos de Wrede. Así mismo, Jesus Seminar mantiene la visión de un Jesús sabio, contracultural, relacionado con los cínicos de su tiempo. En lugar de recorrer el camino de Wrede, será mejor recorrer el camino de Schweitzer, concediendo mayor valor histórico a los evangelios, considerando innegable el carácter escatológico de Jesús, "en la medida

El año 1980 es una fecha convencional que sirve como referencia. Fue entre 1965 y 1975 donde se comenzaron a enunciar los temas de discusión que aparecerían con mayor claridad a partir de 1980. Cf. Ibíd., 527. En este sentido podríamos hablar de Pannenberg como uno de los pioneros que, con su teología -y según la datación de sus obras-, abrió las puertas a la «Tercera búsqueda».

6 Ibíd., 528. 532. Particular importancia se subraya para escritos apócrifos como el evangelio de Tomás, el evangelio de Pedro, el evangelio secreto de Marcos, el papiro Egerton 2. Son testigos excepcionales con tradiciones paralelas o anteriores a los evangelios sinópticos. Crossan, autor identificable con la «Tercera búsqueda», los llama «los otros cuatro evangelios», alternativos casi al punto de ser considerados los cuatro evangelios «canónicos» consagrados por la crítica histórica. 
en que se resitúa a Jesús en el judaísmo de su tiempo se impone esta visión escatológica"7.

5. Se le dio un «golpe de estado» a un personaje representativo, como Rudolf Bultmann, y los resultados de sus trabajos fueron profundamente revisados.

6. Se llegó entonces a un mejor conocimiento del judaísmo antiguo, caracterizado por su pluralismo, más allá de toda visión monolítica y homogénea, para contextualizar allí al judío Jesús8.

7. También fue destronado el "Criterio de discontinuidad o dessemejanza". La voluminosa obra de John Meier, Un judío marginal, iba en esa dirección. Este mismo estudioso de la cristología, nos dice claramente:

"...el criterio de discontinuidad, en vez de proporcionarnos un mínimo asegurado de material sobre Jesús, acaba ofreciéndonos una caricatura al divorciar a Jesús del judaísmo que influyó en él y de la Iglesia en la que él influyó. Jesús fue un judío del siglo I cuyos hechos y dichos la Iglesia primitiva veneró y transmitió. Una completa ruptura con el ambiente religioso inmediatamente anterior o inmediatamente posterior a él es inverosímil a priori. De hecho, si Jesús hubiera sido tan "discontinuo" y único, si hubiera estado tan apartado del flujo de la historia anterior y posterior a él, habría resultado ininteligible para prácticamente todo el mundo. Para ser un maestro eficaz (y Jesús parece haberlo sido, en opinión de todos los expertos) hay que adaptarse a las concepciones y puntos de vista de aquellos a los que se enseña, incluso cuando la finalidad es cambiar esas concepciones y puntos de vista. Por original que fuera Jesús, para alcanzar eficacia como maestro y comunicador tuvo que someterse a los imperativos de la comunicación, los imperativos de su situación histórica. Trazar una imagen de Jesús completamente al

Rafael Aguirre, op. cit., 304. No es una invención de la Third Quest la contextualización judía de Jesús. Sucedió que la New Quest había ignorado el trabajo de autores judíos. Ibíd., 306.

8 Álvaro Cadavid, op. cit., 529. 536; el rigorismo posbultmaniano pensaba que al hablar de judaísmo se enfrentaban tan solo con el rigorismo legalista en un judaísmo unitario y normativo. Los testimonios escritos dan cuenta de tal pluralidad: manuscritos del mar muerto, targums, literatura apócrifa judía, textos rabínicos. Siendo así, es necesario contextualizar a Jesús, pero es necesario también contextualizar el mismo judaísmo. Rafael Aguirre, op. cit., 310. 
margen o en contra del judaísmo y el cristianismo del siglo I equivale a colocarlo fuera de la historia"9.

En su lugar fue debatido un nuevo "Criterio de plausibilidad histórica", que afirma como históricamente plausible todo lo que revele una relación de continuidad y discontinuidad, simultáneamente, con respecto al judaísmo anterior a Jesús y con respecto al cristianismo naciente ${ }^{10}$. El criterio de plausibilidad es más integrador, sabe articular la tensión entre continuidad y discontinuidad de Jesús respecto a judaísmo y cristianismo.

"(llamado también de criterio de disimilitud, de originalidad o de irreductibilidad dual) se centra en las palabras o hechos de Jesús que no pueden derivarse del judaísmo de su época ni de la Iglesia primitiva posterior a él. Ejemplos (...) su radical prohibición de todo juramento, su rechazo del ayuno voluntario para sus discípulos, su total prohibición del divorcio. Este criterio es a la vez el más prometedor y el más erizado de problemas: (...) presupone lo que no poseemos: un conocimiento seguro y completo de cómo eran el judaísmo en la época de Jesús y el cristianismo inmediatamente posterior a él, y de lo que ambos podían o no decir. (...) Con todo, la labor histórico-crítica realizada en las dos últimas centurias ha proporcionado notables progresos a nuestro conocimiento del judaísmo y del cristianismo del siglo I. Además, no podemos ignorar la evidente diferencia que existe entre conocimiento acerca de Jesús, por un lado, y conocimiento acerca del judaísmo y del cristianismo del siglo I, por otro. Poseemos documentos del siglo I que proceden directamente de tales ámbitos religiosos -Qumrán, Josefo y Filón para el judaísmo, y la mayor parte del NT para el cristianismo-, (e) importantes hallazgos arqueológicos. En cambio, no disponemos de unos documentos similares que procedan directamente de Jesús (...) si tuviéramos que esperar a alcanzar un conocimiento pleno que excluyese una revisión posterior, tendríamos que posponer hasta la parusía todos los trabajos sobre el NT (...) Naturalmente, la misma necesidad de comprobación y corrección es aplicable al énfasis en la continuidad histórica de Jesús con el judaísmo y el cristianismo primitivo. En el caso del judaísmo en particular, siempre tenemos que preguntarnos: ¿̇con qué clase de rama o tendencia del judaísmo era "continuo" Jesús en una acción o dicho determinados? Además, al igual que no podemos decidir que Jesús tuvo que ser discontinuo con el judaísmo de su tiempo en tal o cual asunto, tampoco es posible establecer a priori que tuvo que estar de acuerdo con el judaísmo en todas las cosas (...) Un problema ulterior que suele complicar el criterio de discontinuidad es de tipo terminológico. Los expertos dirán que este criterio aísla lo que es "único" de Jesús. La "unicidad" es un concepto escurridizo en la investigación histórica. Algo similar se puede decir de la unicidad de Jesús. Al considerar un determinado dicho o hecho de Jesús, quizá sea mejor hablar de lo que es "notablemente característico" o "insólito" en la manera de expresarse o de actuar de Jesús, en vez de emplear el término "único" a cada paso (...) es aconsejable la modestia a la hora de formular una afirmación. Similarmente, cuando hablemos de la actuación pública de Jesús, tal vez sea más prudente recurrir a locuciones como "las cosas concretas que realizó Jesús" (p. ej., exorcismos, curaciones por la fe), en lugar de aseverar que un determinado relato nos cuenta exactamente lo que hizo Jesús en una ocasión particular. La misma distinción se puede aplicar a la tradición de los dichos considerada en su conjunto. Podemos albergar cierta esperanza de conocer lo esencial del mensaje de Jesús, "las cosas" que él decía de una manera usual o característica (ipsissima vox). Raramente, por no decir nunca, podremos afirmar con razón que hemos recuperado sus exactas palabras (ipsissima verba)". John P. Meier, "Las raíces del problema y la persona", en Un judío marginal, Nueva visión del Jesús histórico. Tomo I (Navarra: Verbo Divino, 1998), 168-171; Santiago Guijarro Oporto, op., cit., 32. En ese mismo sentido: "La investigación de los últimos años se ha centrado, sobre todo, en las palabras de Jesús, porque se consideraba que contenían una tradición anterior a la pascua, pero últimamente se ha insistido en la importancia de la tradición sobre los milagros y en general sobre la actuación de Jesús como marco para entender sus enseñanzas", Ibíd., 31.

10 Álvaro Cadavid, op. cit., 534. Rafael Aguirre, op. cit., 310-312. Pero, además, junto a la contextualización judía se incluyen la contextualización de Jesús en el imperio romano, y la contextualización de Jesús en sus seguidores. 
8. La contextualización se vuelve una tarea importante de cualquier historiador al cual se le exige situar aquello que se sabe sobre Jesús, en el marco de la historia del judaísmo de su época, y ambientar tales datos en el escenario de aquella sociedad con las herramientas de la historia antigua y las ciencias sociales.

La Third Quest se ha tomado en serio el judaísmo de Jesús, pues las fuentes que hoy se poseen permiten argumentar con fuerza la influencia religiosa y cultural del judaísmo nativo de Palestina en la vida y el mensaje de Jesús. Es tan cierto y completo el judaísmo de Jesús que si se dice que Jesús es verdaderamente hombre y verdaderamente Dios, hay que afirmar que la humanidad de Jesús no es algo meramente genérico, pues es verdaderamente hombre porque es precisa y verdaderamente judío. Es este un dato que debe incorporarse a hoy cualquier reflexión cristológica ${ }^{11}$.

A este apunte conclusivo, debemos agregar lo dicho por Rafael Aguirre quien complementa, así: "...ha de ser una visión que sea capaz de explicar el conflicto intrajudío, la crucifixión por los romanos, y la pervivencia de un movimiento de seguidores que reivindicaban su memoria"12.

Pannenberg y su obra Fundamentos de cristología, se sitúan en el inicio de la "Tercera búsqueda" del Jesús histórico, y es pionero de una reflexión que aun no tenía su máximo desarrollo.

\subsection{Una crítica al argumento de la resurrección en Pannenberg}

No es posible obviar el gran aporte hecho por Pannenberg a la teología. Intentaremos aprender de un gran teólogo y haremos lo mismo con los aportes cristológicos actuales al tema común que nos reúne, cual es la resurrección, teniendo como marco referencial que la cristología hace, como todas las ciencias, pasos y avances, de manera profunda. Pero una crítica no descalifica la novedad generada en cierta época, del mismo modo que la novedad actual nunca podrá tener la última palabra.

Álvaro Cadavid, op. cit., 537. Sobre el valor de los textos del helenismo, también Cf. Andrés Torres Queiruga, Repensar la Resurrección (Madrid: Trotta, 2005), 41. 
En el completo estudio hecho por José Caba ${ }^{13}$ se hace una síntesis del mismo artículo de la obra Fundamentos de cristología de Pannenberg. Antes de la aproximación exegética, Caba hace un análisis de las aproximaciones teológicas al tema de la resurrección, y al terminar la síntesis del artículo que aquí también estudiamos, realiza la formulación de la crítica respectiva. Esta se focaliza en los siguientes puntos sobre el tema de la resurrección en la obra del teólogo W. Pannenberg:

- Con este autor, la resurrección alcanzó el puesto que se merecía: dejó de ser un simple corolario dentro de la cristología, para convertirse en la piedra angular que la fundamenta.

- La resurrección deja todo aspecto de subjetivismo, lo que caracterizaba a la cristología bultmaniana.

- Pero, la resurrección se vuelve tan apoteósica, que llega incluso a eclipsar la fe.

- La resurrección es real en cuanto es histórica, porque en Pannenberg todo referente teológico se sella con la nota de la historicidad; sin embargo, un concepto tan amplio de historia lleva en sí la semilla de la ambigüedad. Dios se relaciona con la historia, se entrecruza con ella, pero por abarcar en su realidad toda la historia, se escapa también de ella.

- La resurrección trasciende la historia. Podemos conocer el punto de partida del Resucitado, es decir, su muerte, pero no nos es verificable el punto de llegada cuando se realiza el tránsito de este mundo al mundo de Dios.

- La resurrección de Jesús entra en la historia no por sí misma sino por los relatos de las apariciones y por el sepulcro vacío. Cuando a la resurrección se la reviste de historicidad, se le despoja de su aspecto de misterio. Incrustada en tiempo y espacio queda como un dato del pasado, y por tanto, se accede a ella solo por la historia y la investigación histórica. La fe se basa no sólo en la seguridad 
del hecho histórico, sino también en la Palabra y autoridad de Dios. La certeza de la resurrección queda debilitada cuando sólo posee la probabilidad que le da la investigación histórica.

- La fe no necesita ser ampliada hasta la plena historicidad. El uso metafórico en el lenguaje de la fe en la resurrección, no implica falta de realidad, sino que tal acontecimiento no puede ser abarcado totalmente por la propia experiencia y por la historia.

- Aceptar que la luz de la resurrección lo ilumina todo, no implica que todo lo anterior carezca de luz propia ${ }^{14}$. El Cristo pascual es deslumbrante en su revelación definitiva, pero las acciones y palabras del Jesús prepascual, tienen la validez reveladora de lo que Dios dice en Jesús.

- No se justifica interpretar el legado paulino (esp. 1Co 15, 1-11) como histórico, y los evangelios como legendarios. Tiene gran valor lo dicho y escrito por Pablo, pero ello no oscurece el aporte de los evangelios.

\subsection{Lo que Pannenberg piensa frente a sus críticos}

A la distancia de 21 años de su libro Fundamentos de cristología, Pannenberg reconoce que "no es posible comunicar algo realmente nuevo sin ser malentendido. Inevitablemente el lector y el oyente intentan encajar lo que se les comunica en su propio y previo marco de comprensión; de ahí que cuanto más novedosa sea la teoría que se les ofrece más fácilmente tienden a desfigurarla"15. Y aunque no se trata de desfigurar lo planteado por Pannenberg, sí, en cambio, se pretende una aproximación a sus mismas conclusiones por caminos diferentes.

Hay coincidencia con Pannenberg cuando afirma: "No es posible defender las afirmaciones de la fe del carácter problemático, sin

14 "Al NT le interesa menos el desarrollo realista de la resurrección. Es verdad que sus fórmulas y sus relatos señalan hacia una experiencia. Pero en los detalles de la misma el NT es justificadamente parco. Únicamente dice y difunde lo que es necesario para la finalidad teológica. No impone forzadamente ninguna determinada teoría acerca del marco histórico". Andrés Torres Queiruga, op. cit., 41.

15 Manuel Fraijó, "Pannenberg enjuicia su propia teología. Entrevista...", en El sentido de la historia. Introducción al pensamiento de W. Pannenberg (Madrid: Cristiandad, 1986), 263-286. 
renunciar también a su pretensión de verdad"16. Y, en este sentido, unido a Heidegger, nuestro autor -Pannenberg- piensa que "independientemente del significado (o del sentido) que atribuyamos a los acontecimientos y sus contenidos, estos poseen en sí mismos significado y sentido; lo demuestra el hecho de que el sentido que nosotros les atribuimos puede adulterar el verdadero significado de los acontecimientos ${ }^{\prime 17}$.

Tal vez podríamos apoyarnos, para nuestro procedimiento, en lo que el mismo Pannenberg, dice al considerar que el significado de cada acontecimiento depende de un contexto, y cada contexto limitado se inserta en conexiones más amplias, a su vez relacionadas de una u otra forma, con el carácter procesual de la realidad. Desde esta perspectiva, se concluye que tanto el sentido como el significado dependen del contexto de sentido (desconocidos para nosotros) que en el proceso de una historia no ha alcanzado aun su meta definitiva, y que solo se pueden comprender en forma de anticipación ${ }^{18}$. Este es el programa de Pannenberg, y nos acercamos a él escudriñando cómo se fue «anticipando» la anticipación, indagando cómo nació y evolucionó aquella prolepsis.

En lo que sigue, se propone reflexionar sobre dos categorías cristológicas pannenberianas centrales en su obra, a saber, la muerte y resurrección y el tema apocalíptico.

\section{Muerte y resurrección}

El artículo que nos ocupa, La Resurrección de Jesús como fundamento de su unidad con Dios ${ }^{19}$, pertenece a una obra cuya edición alemana es de 1964 y la edición española, apareció casi diez años más tarde, en 1973. Pero hay que tener en cuenta algunos presupuestos (del segmento "La divinidad de Jesucristo") de la obra Teología sis-

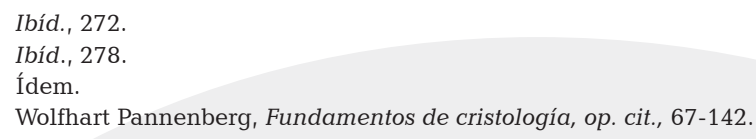


temática del mismo Pannenberg, quien hacia 1991 replantea ideas suyas de la producción literaria anterior.

\subsection{Significación de la muerte de Jesús}

La condición de la muerte de Jesús adquiere una especial importancia que supera una significación secundaria ${ }^{20}$. En efecto, en el segundo volumen de su Teología sistemática, Pannenberg se expresa de la siguiente manera:

Si la muerte de Jesús en la cruz hubiera sido un suceso extrínseco a él mismo y sin conexión con su mensaje y actuación, resultaría teológicamente irrelevante, una lamentable consecuencia de un malentendido por parte de los romanos, que tomaron a Jesús por un agitador político. Pero si existe una conexión, fundada en el mensaje de Jesús, entre la ambivalencia que rodeó a su propia persona, y las consecuencias que ella provoca de rechazo, detención y entrega a Pilato para su condena como agitador, entonces todas estas consecuencias tienen que ver con la misión divina de Jesús y, por tanto, finalmente con Dios mismo. Si escándalo y cruz eran las consecuencias (provisorias) de la pretensión que implicaba el mensaje de Jesús con respecto a su propia persona, entonces fue precisamente la presencia de Dios en él (en cuanto simple hombre) lo que lo llevó hasta la cruz y hasta la situación de abandono por Dios. Y esto es justa y especialmente válido si el conocimiento que Jesús tenía de la presencia de Dios en su actuación, no era una pura ilusión. La ambivalencia que todo ello suponía solo podía eliminarse mediante la resurrección del Crucificado ${ }^{21}$.

Dejar como ambigua esa definitiva condición de la muerte en cruz, no es viable porque esta condición es el factor sin el cual, el acontecimiento de la resurrección, no sería comprendido, y menos interpretado. En la nota $46^{22}$ de su obra Fundamentos de cristología, nos parecía hallar un tentativo ${ }^{23}$ de aclaración al respecto, -si es que el teólogo estaba colocando la muerte en un segundo plano de

Ibíd., 82. Cf. Álvaro Cadavid, op. cit., 527. Desde la «Tercera búsqueda» se plantea la originalidad de Jesús precisamente por el conflicto que tuvo con las autoridades judías y que le llevaron a la muerte. Wolfhart Pannenberg, Teología sistemática, op. cit., 371.

Wolfhart Pannenberg, Fundamentos de cristología, 84.

Dicho tentativo consiste en el hecho de que la muerte de Jesús no parecía ser tenida en cuenta, y sólo la resurrección adquiere patente de legalidad para hablar de la prolépsis en la pretensión de poder del Jesús prepascual. En efecto, nótese la nota 56, cuando dice: "Jesús consideraba su misión como circunscrita a Israel, de modo que la difusión universal del mensaje salvífico a los paganos seguía estando reservada para el futuro de Dios. No precisamente a partir del mensaje de Jesús, sino solo a partir de su resurrección (y exaltación) se inicia una camino directo hacia la misión entre los gentiles". Ibíd., 88. 
significación-, al decir: "es verdad que la muerte de Jesús ha sido concebida a la luz de la pasión profética", y reconocía que "la pasión por sí sola no constituye, la confirmación sino solo el destino, inevitable en este mundo malo del profeta y del justo en general". Si era de esta manera, también en este caso, se imponía la pregunta de si la resurrección por sí sola -sin tener en cuenta la muerte- constituiría la confirmación y justificación del justo. Aquí valdría la pena tener en cuenta no solo la profecía bíblica respecto a la justificación del Siervo sufriente y perseguido de los cánticos de Isaías, sino además la promesa de resurrección para los mártires ${ }^{24}$ en la literatura bíblica y apócrifa, como sigue ${ }^{25}$ :

En 1Enoc 22-27 (s.III a.C), Abel es el prototipo de los inocentes perseguidos. Él acusa a Caín y su descendencia. La preeminencia de Abel indica que la muerte violenta y la falta de juicio divino contra los perpetradores de este tipo de crimen se vuelve una preocupación fundamental del autor. En 1Enoc 92-105 (s. II a.C.), la injusticia invade el mundo del autor. El rico y poderoso oprime al pobre y justo, quien sufre a pesar de su justicia y su piedad. En consecuencia, se debe considerar que hay una recompensa y un castigo. En Jubileos 23, 11-31, escrito un año o dos antes del libro de Daniel, se describe la lucha sangrienta entre los judíos piadosos y los helénicos que culmina en la inmisericorde intervención del gobierno Sirio. A causa de su pecado el pueblo ha acortado el lapso de sus días, pero cuando ellos vuelven a los mandatos de Dios, el lapso de su vida obtiene una fabulosa extensión, como la de los primeros patriarcas. El autor de

Ibíd., 98. Cf. Los testimonios de los apócrifos considerados -en su Fundamentos de Cristología-, por Pannenberg, solo que él se valía en aquella obra de ellos para enfatizar el argumento de la resurrección de los muertos, y no para la resurrección de Jesús. Sobra decir que estamos hablando de la justificación del justo, perseguido y torturado. No se trata de una muerte cualquiera, ni de la muerte (en cruz) de uno cualquiera, no se trata de la muerte de Buda, en la paz de su meditación, ni de la muerte de Mahoma, en feliz ancianidad. “...en la vida de Jesús tiene que encontrarse una razón suficiente que explique, por una parte, el hecho más indiscutible y escandaloso que le aconteció (la muerte en cruz) y, por otra parte, el fenómeno no paragonable que le prosiguió. La contextualización plausible de Jesús en el judaísmo y en sus seguidores no excluye -al contrario- exige la búsqueda de su especificidad personal". Rafael Aguirre, op. cit., 314.

25 Todo el parágrafo correspondiente a esta nota en el texto dependen de Malcolm Peel, "Resurrection (Early Judaism and Christianity)" in Anchor Bible Vol 5 (New York: Doubleday, 1992), 684-688. A estos testimonios se pueden agregar todavía, 2Baruc y 4Esdras 7, que enfatizan la recompensa y el castigo merecido por las obras, su contexto es el s. I, como respuesta la destrucción de Jerusalén en el año 70 d. C.; Cf. también una aproximación similar en Wolfhart Pannenberg, Teología sistemática, op. cit., 375-376. 
este texto usa de nuevo el lenguaje de Is 65, (20-22) para describir el tiempo final. Todo esto, desde los textos apócrifos o pseudoepigráficos. En los textos Deuterocanónicos, por lo general contemporáneos a los anteriores, encontramos ideas paralelas: Daniel 12, 1-3, este escrito se compuso entre los años 165-167 a.C, con el fin de fortalecer a lo judíos piadosos en la persecución de Antíoco Epífanes, y esta parte breve responde al conjunto de Daniel 10-12 compuesto como un apocalipsis que describe los eventos de la historia de Israel desde Darío el Medo hasta Antíoco (11, 2-45). Según Dan 12, 3 los maestros sabios de la comunidad, que han animado a muchos a caminar por la vía de la justicia serán exaltados gloriosamente entre las estrellas y las huestes angélicas. Aquí el autor diseña una exposición tradicional derivada del último canto del Siervo de YHWH (Is 52, 13-53, 12). 2Mac 7, a finales del s. II se compone este texto, que relata la legendaria muerte de los siete hermanos con su madre. Condenados a la muerte por una corte humana ellos esperan la vindicación de la corte divina. Dios mismo restaurará la vida y los miembros que Antíoco ha destruido. La resurrección corporal es la contraparte de la destrucción corporal. La vindicación es en especie. Los jóvenes del relato son voceros de Dios, ellos sufren por su oficio profético, y por esta razón, ellos serán vindicados (Is 50, 7-9). Sabiduría de Salomón 1-6, (inicios del s. I) como una disputa sobre la inmortalidad (cfr. 1Enoc 102-104). Desde que la muerte es aniquilación, uno podría gozar la vida incluso a expensas de otros (2,1-11). Este relato está basado en textos como Gn 37-45, Ahicar, Ester, Daniel 3. 6. Pero aquí hay una diferencia: el protagonista es exaltado y recibe vindicación en la corte celestial, la recompensa y los castigos son eternos y trascienden la muerte física. La escena de la exaltación celestial del justo ha sido establecida por y desde Is 52, 13-53, 12. Como en el Deuteroisaias (y Gn 37-45, y Daniel 3.6), el protagonista es un vocero de Dios. Esta tradición según el modelo de Isaías, se halla detrás de Daniel 12, 3. En Sab 1-6 el caso del perseguido y exaltado es un paradigma del juicio de Dios para todo el pueblo, quien será recompensado o castigado por sus obras $(3,10-4,15)$.

Como puede observarse en esta síntesis de deuterocanónicos y apócrifos, la muerte y la resurrección con sus variantes, está asociada a la idea del martirio y del sufrimiento, especialmente a causa de la persecución. La base que ilumina y genera esta esperanza radica y depende fundamentalmente de las lecturas, relecturas o actualizaciones del Siervo sufriente del segundo Isaías. Así es posible afirmar con Pannenberg: "La resurrección de Jesús es el fundamento de la fe cristiana, no como un hecho aislado, sino en su relación con la misión terrena de Jesús y con su muerte de cruz (...) esta relación no es como algo añadido al acontecimiento de la resurrección de Jesús; 
es inseparable de ese acontecimiento en cuanto tal, pues la resurrección es algo que acontece precisamente a Jesús, el crucificado"26.

En la misma cita ya mencionada (nota 46) de sus Fundamentos de cristología ${ }^{27}$ continuaba diciendo Pannenberg:

el fracaso y la desgracia no constituyen ningún signo evidente de la justificación, ya que normalmente son, dentro del orden divino de los acontecimientos, un castigo para el pecador. Frente a esto, la teología apocalíptica de la pasión solo podía justificarse en tanto que, en contra de las apariencias, el fracaso terreno no debiera colocar necesariamente al profeta en la injusticia. La confirmación de su mensaje, sin embargo, por medio de su cumplimiento sigue en suspenso. ¿Qué sería de un profeta cuyas palabras no se hubieran cumplido, aun cuando hubiese fracasado lamentablemente? También con respecto a los judíos que pretendían ser el Mesías solía guardarse silencio después de su fracaso. Según la lógica de Mildenberger, precisamente por razón de su fracaso deberían haberse anunciado y creído justamente como mesías.

En esta amplia citación Pannenberg ponía en el mismo nivel no solo a los mesías que se hicieron frecuentes en la Palestina apocalíptica del s. I, sino que haciéndolo de esta manera, terminaba colocando en el mismo nivel a los grupos que están tras las expectativas mesiánicas, como si fuera un consenso que todos los grupos se comportan de la misma manera.

Es necesario distinguir entre movimientos mesiánicos y proféticos ${ }^{28}$. Los primeros eran aspirantes a la realeza por la toma del poder político; y los proféticos, buscan la salvación de los grupos marginados, entienden la salvación como una transformación del mundo por una intervención divina inminente, tienen un profeta o líder carismático, se les considera como movimientos peligrosos, al punto que, asesinando a su líder, se elimina el movimiento; lo cual está atestiguado, sobre todo, en la obras de Flavio Josefo. El milena- 
rismo de este movimiento profético, con el que se identifica a Jesús, tiene estas características:

- $\quad$ Surge en un momento de crisis acelerada, expresando anhelos e intereses de grupos marginados.

- Su protesta busca un cambio radical para un futuro próximo, que será obra de Dios.

- Su profeta carismático, Jesús, abre la perspectiva de una alternativa social con un grupo de seguidores.

- Confiere a los sectores marginados la conciencia de una nueva identidad con la esperanza de ser protagonistas de lo que ahora les es negado.

Decir que fracaso y desgracia, no son un signo evidente de la justificación, dejaba una sensación de parcialidad, y dejaba de lado objetivamente que tal fracaso está integrado en la perspectiva del que más tarde sería justificado ${ }^{29}$.

Así mismo, nos resulta extraño, afirmar que el fracaso y la desgracia son normalmente el castigo del pecador. Y no significa que no lo sea, significa más bien que una afirmación como esta podría ser respaldada a la luz de la teología del Siervo sufriente, en la cual el Segundo Isaías, no separa fracaso y triunfo. Gal 3, 13 recoge esa condición de Jesús que se hace maldito a causa de la ley ${ }^{30}$.

"Puesto que en Hch 7, 55s encontramos un mundo conceptual similar, Mc 14, 58 apuntó ya en este sentido, es aconsejable atribuir Mc 14,62b a la llamada redacción anterior a Marcos. Esta redacción estuvo, pues, interesada en presentar la pasión como un acontecimiento que precede al fin". En estas palabras se plasma la unidad, bajo la perspectiva apocalíptica, del acontecimiento unitario de pasión-muerte-resurrección, o al menos, nos vemos llevados a reconocer que en un estadio premarcano, la pasión -toda ella, y no solo la resurrección- fue presentada como el acontecimiento indispensable, que precedía el fin del mundo. Cf. Joaquin Gnilka, El evangelio según San Marcos, vol II. (Salamanca: Sígueme, 2001), 320-321.

30 Pannenberg no compartía con Pablo la exegesis que él hace respecto a la condición de Cristo como un maldito a causa de la ley. Pannenberg hubiese preferido otro tipo de aproximación por lo que manifestaba en Fundamentos de cristología, su rechazo lo expresaba con estas palabras: "Estos han sido los presupuestos de la exégesis judía en el tiempo cristiano-primitivo, pero no los nuestros". Wolfhart Pannenberg, Fundamentos de cristología, op. cit., 309. En la obra Teología sistemática, Pannenberg comenta Gal 3, 13 algunas veces junto a otros textos paulinos, pero no hace comentarios alusivos a la exegesis judía de ese texto. Wolfhart Pannenberg, Teología sistemática, op. cit., 448-470. 
Pero, por otra parte, y en línea con lo anterior, cuando Pannenberg se enfrenta con la misión entre los gentiles, la proclama como una misión motivada por la resurrección escatológica de Jesús como resurrección del crucificado ${ }^{31}$ y así Pannenberg asume un aspecto esencial que parecía separado o aislado del aspecto resurrección. Los gentiles -diríamos, para mejor comprensión, los «judeogentiles»- recibieron el anuncio de Aquel crucificado y maldito a causa de la ley, y fueron incluidos en la salvación por esa misma crucifixión. Y ya que Jesús fue rescatado de la muerte con su resurrección, se demostró que la maldición de la ley no tenía eficacia, y así los judeogentiles podían acceder a la salvación sin necesidad de la ley. Así lo confirma Pannenberg:

Resulta instructivo el hecho de que Pablo no haya fundamentado originariamente la misión entre gentiles en la llamada a las promesas universalistas de los profetas veterotestamentarios con respecto al fin de los tiempos, sino a partir del acontecimiento de Cristo y, concretamente, a partir de la crucifixión de Cristo $(\mathrm{Gal} 3,13)$ que sin duda fue concebida ya a la luz de la resurrección ${ }^{32}$.

Pero la resurrección, como medio de interpretación retrospectiva, no implica un partir de cero, sino que todo el pasado próximo y el pasado remoto tenían ya una carga teológica y una posibilidad de interpretación desde lo sociológico.

La categoría sociológica de la Autoestigmatización, como proceso por el cual se asume el estigma y se le reinterpreta positivamente como crítica del orden social y semilla de alternativa radical. Es la tarea del líder carismático: marginado, sin hogar, itinerante, sin dinero, crítico con el honor como se entendía culturalmente, proponiendo valores nuevos como el amor a los enemigos, la no violencia, el servicio al humilde, con una esperanza para realización de lo que se espera en el futuro, esto es Jesús, cuyas actitudes provocan el reforzamiento de la identidad del grupo y su esperanza en una recompensa futura, en él se unen el profeta escatológico y el maestro de sabiduría. El grupo de seguidores aceptará la máxima estigmatización, la crucifixión, y en un proceso de autoestigmatizacion convertirán la cruz en lugar de generación de valores positivos y socialmente críticos. "Sus seguidores verán en el crucificado la realización máxima de los valores que Jesús anunció y, más aun, dirán que Dios mismo ha confirmado esa forma nueva de entender la vida, esa «revolución de los valores» al re- 
sucitarle de entre los muertos". La interpretación de la comunidad de la muerte deshonrosa de Jesús solo fue posible porque habían aprendido ese proceso en la actitud y enseñanza del mismo Jesús ${ }^{33}$.

Por lo menos en el caso del anuncio a los gentiles, Pannenberg concluye con vehemencia clarificadora: "Naturalmente, no sólo la noticia de la crucifixión -y permítasenos interrumpir diciendo, !!! no solo la noticia de la resurreccióniii- de Jesús ha hecho que Pablo se convirtiese de un perseguidor de la comunidad cristiana en un apóstol de los gentiles, sino principalmente su encuentro con el crucificado como resucitado"34. Este es el proceso indispensable y necesario, pero żocurre solo en Pablo? Sirva de colofón a esta parte las mismas palabras de Pannenberg, en su Teología Sistemática, al establecer el sentido de la muerte de Cristo como expiación:

Una vez que su muerte se entendió como expiación, esta interpretación pudo ponerse en relación con la representación que se daba de hecho en que Jesús hubiera padecido la muerte en lugar de sus jueces y de todo el pueblo representado por ellos. Probablemente, esta realidad se halla en el fondo de las afirmaciones paulinas de Gal 3, 13; 2Cor 5, 21 y Rom 8, 3. En efecto, estas afirmaciones difícilmente se entienden sin una relación con la situación de la condena y la ejecución de Jesús en la que él fue hecho pecado y cayó bajo la maldición de la ley. Dios no solo «hizo pecado» a Jesús -a través de la actuación de su jueces humanos-, sino que le hizo también padecer en «nuestro» lugar (no sólo en lugar de sus jueces judíos o del pueblo judío) el castigo que corresponde al pecado en cuanto tal y que nace de su misma naturaleza, la pena de muerte como consecuencia de la separación de $\operatorname{Dios}^{35}$.

\subsection{La resurrección en la situación histórico-tradicional del cristianismo primitivo ${ }^{36}$.}

Valdría la pena analizar y repensar la siguiente afirmación, tal como lo expresaba Pannenberg en su primera producción teológica:

Solo para la segunda generación de testigos neotestamentarios, para Marcos, Mateo, Lucas, Juan, para los autores de las cartas deuteropaulinas y de la carta a los hebreos, fue claro que la resurrección de Jesús no constituyó todavía el comienzo del desarrollo continuo de los

33 Rafael Aguirre, op. cit., 324.

34 Wolfhart Pannenberg, Fundamentos de cristología, op. cit., 90.

35 Wolfhart Pannenberg, Teología sistemática, op. cit. 458-459.

36 Wolfhart Pannenberg, Fundamentos de cristología, op. cit., 82-92. 
acontecimientos finales, sino solo un acontecimiento particular ocurrido únicamente en Jesús. En este punto surgió el peligro de perder de vista la conexión existente entre la resurrección de Jesús y los acontecimientos escatológicos de la resurrección universal de los muertos y el juicio (...) allí donde desaparece la tensión entre el presente y espera del futuro, el acontecimiento de la resurrección de Jesús, pierde su intrínseca significación originaria, es decir, la significación que le es propia dentro de su contexto histórico-tradicional originario, esto es: en el horizonte de la espera apocalíptica del futuro (...) para los judíos contemporáneos, en tanto que eran participes de la espera apocalíptica, el acontecimiento de la resurrección no requería que fuese interpretado, sino que hablaba por sí mismo ${ }^{37}$.

La crítica reciente no considera que todo dependa únicamente de la segunda generación. Será necesario crear este interrogante: ¿Consideraba la exégesis de hace algunos años, darle mayor importancia a los textos escritos y olvidaba con relativa facilidad, que los textos llegaron a ponerse por escrito, gracias a que la oralidad de los mismos tenía ya un trayecto recorrido? Si el asunto hay que plantearlo al nivel de lo subrayado por Pannenberg, cuando afirma que "Solo para la segunda generación de testigos neotestamentarios, (...) fue claro que la resurrección de Jesús no constituyó todavía el comienzo del desarrollo continuo de los acontecimientos finales, sino solo un acontecimiento particular ocurrido únicamente en Jesús" ${ }^{\prime \prime 3}$, entonces estaríamos dejando un vacío que deja a la segunda como una generación tímida que apenas veinte años después de los eventos fundantes comenzó a dilucidar la configuración de las pretensiones de poder por parte de Jesús, y la primera generación corre el peligro de quedar como si fuese indiferente ante el acontecimiento ocurrido pocos años antes delante de los testigos que no tenían, por lo tanto, nada que decir, ni de qué dejarse impactar.

Una crítica de este tipo puede dar la impresión de una lectura superficial de Pannenberg, quien realmente hace una caracterización historizada de la primera generación de cristianos. Es verdad que hay una activa oralidad, aunque no institucionalización de la fe 
bajo la experiencia histórica de la resurrección. Así se hace oír Pannenberg, al subrayar la experiencia cristiana en vivas tradiciones, incluso revisando las posturas del escrito Fundamentos de cristología:

La tradición de las apariciones se encuentra en su forma más antigua en Pablo (1Cor 15, 3-7). La gran antigüedad de la enumeración que allí se hace de las apariciones y la circunstancia de que estos datos procedan inmediatamente de un hombre que conocía personalmente a los testigos que menciona, o al menos a la mayoría de ellos, incluyendo en el ultimo lugar de la lista la aparición de la que el mismo fue objeto (1Cor 15, 8), no pueden ponerse en duda ni aún en el caso de que hubiera sido el mismo Pablo quien hubiera reunido por primera vez los diferentes datos en esta lista, en apoyo de la argumentación desarrollada en su carta ${ }^{39}$.

Sirva esta aclaración para recordar que la vivacidad de la oralidad y la literatura no tenían aún criterios de canonicidad desde al ámbito judeo-cristiano.

Entonces, podemos acertar que no hay un vacío entre la comunidad original y los inicios de la producción escrita ${ }^{40}$. A la muerte de Jesús, sus seguidores tenían delante un «arsenal» literario para interpretar la vida y muerte de Jesús: Antiguo Testamento, escritos greco-romanos; agréguese a ello, el patrimonio de la literatura judía, apócrifa y pseudoepigráfica, y muchos otros elementos escritos y orales, que poco a poco se fueron uniendo y complementando.

Valga mencionar que el mismo Pannenberg considera algunas expresiones como "formulación tradicional"41 -como aquella que se refiere a Jesús como primogénito de entre los muertos-. También aquí merece mencionarse el hecho de que tales formulaciones deben tener pasado y raíces que sostengan su condición presente en la mentalidad de los cristianos del siglo I. En efecto, las citas tomadas de la Biblia, por ahora y en este caso, se refiere a textos neotestamentarios con una evolucionada cristología, como el libro del Apocalipsis. La tradición,

39 Wolfhart Pannenberg, Teología sistemática, op. cit., 382.

40 Hernán Cardona, Los cristianos del 30 al 50 e.c. (Medellín: Universidad Pontificia Bolivariana, 2003), 55-60; cf. también Sergio Zañartu, "Reseña de 'Jesús. Los orígenes históricos del cristianismo desde el año 28 al 48 d.C.' de Samuel Fernández Eyzaguirre", Teología y Vida 1-2, Vol. xuIx (2008): 235-238. http://redalyc.uaemex.mx/redalyc/pdf/322/32214688012.pdf. 
por supuesto, no responde solo a los textos que siguen después del evento fundante de la resurrección, sino también a todo lo que hay antes de él, y que a tal evento se refiere.

Es tan claro como que el mismo Pannenberg afirma que "a la proximidad del fin iniciado con la resurrección de Jesús pertenece también la convicción cristiano-primitiva de que el mismo Espíritu de Dios por el que Jesús ha resucitado, vive ya ahora en los cristianos. El Espíritu tiene en el cristianismo primitivo una significación escatológica"42.

\subsection{Más allá de una perspectiva univoca}

Dos aspectos podríamos resaltar en lo que Pannenberg denomina "el concepto de Resurrección de entre los muertos"43. Primero, Pannenberg parece considerar que a la explicitación del argumento de la resurrección de los muertos, no se responde solo con herramientas neotestamentarias, sino también extrabíblicas. Eso es positivo, si se piensa que la tradición va afianzándose y construyéndose con lo que el ambiente vital (Sitz im Leben) ofrece. Está explicita la aceptación de esta idea, cuando Pannenberg afirma: "la futura resurrección de los muertos no es presentada en los escritos apocalípticos de la misma forma, sino de muy distinta manera. En varios aspectos, estas diferenciaciones requieren una investigación histórico-tradicional más precisa todavía"44.

En segundo lugar, y bajo el argumento de las apariciones, Pannenberg parece asegurarse que el testimonio de Pablo es el único que ha puesto por escrito su experiencia sobre la Aparición del Resucitado. De los demás testigos de la Resurrección no se nos transmite ninguna experiencia personal escrita. Parecería que lo que realmente es una consecuencia sea solo una suposición, en efecto, dice: "Es de suponer, no obstante, que lo que puede referirse acerca

43 Ibíd., 92-110. En esta parte hay un uso, aunque no abundante, de escritos apócrifos (Baruc Siriaco, Henoc, 4Esdras). 
de la aparición deparada a Pablo valga en general para el carácter originario de las apariciones pascuales"45. Pero Pannenberg da a entender que hay una tradición anterior al Apóstol de los gentiles, con la que él mismo quería ponerse al mismo nivel con propósitos de autoridad. Por eso a renglón seguido, afirma: "Pablo creía que se le había juzgado digno de una aparición al estilo de las que antes que él se habían deparado a los demás apóstoles"46. De nuevo aquí, Pannenberg le da prevalencia y fuerza a la tradición escrita, en este caso paulina, en desventaja de la tradición oral que ampliamente le precede. Deberíamos tener en cuenta, que si los demás apóstoles -antes de Pablo- vivieron la experiencia de las apariciones del Resucitado, entonces no necesariamente la tradición de las apariciones depende de Pablo. No es posible pensar, que a ellos se les apareció y ellos callaron una experiencia tan particular. Es verdad que no la pusieron por escrito, pero la vivieron antes que Pablo, y muy seguramente la compartieron con sus comunidades, generando en este sentido la tradición respectiva.

\subsection{Varios esquemas}

Partiendo de la clasificación de los textos, es posible una aproximación a dos tipos de tradición ${ }^{47}$ : uno, hay enunciados sobre el acontecimiento y, dos, enunciados sobre la experiencia y el conocimiento. Los enunciados sobre el acontecimiento hablan de resurrección y muerte ("Dios resucitó a Jesús de los muertos"), las que combinan muerte y resurrección ("Jesús murió y resucitó"), entrega y resurrección o despertar y puesto glorioso; luego, una tradición autónoma

$45 \quad$ Ibíd., 95

46 Cf. lo dicho por Pannenberg: "Si volvemos ahora a Pablo, y preguntamos de donde ha sacado propiamente su concepción acerca de la forma de vida de la resurrección, no podemos remitirnos simplemente a la aparición de Jesús resucitado a él deparada, sino que hemos de considerar que ya antes de Pablo ha existido una tradición en la que se ha cultivado la espera de la resurrección de los muertos y en la que Pablo se basa". Ibíd., 97. Aquí Pannenberg subraya la tradición referida a la resurrección de los muertos pero no a las apariciones. Puede ser tan importante la pretensión de legitimación, único motivo que le da validez a las apariciones, pero también, y como más importante aún, es el testimoniar la realidad del resucitado. Ibíd., $117 \S 2$.

47 Ambos enunciados aparecen independientes, pero en un proceso ulterior se combinan en enunciados más desarrollados, uniendo pasión-muerte-resurrección. Andrés Torres Queiruga, op. cit., 49-52. 
que tenía por sujeto al Hijo del Hombre, ejecutado y resucitado a los tres días; los enunciados de experiencia pascual son propiamente los de Pablo. Torres Queiruga clasifica la tradición narrativa de la siguiente manera: relatos de apariciones, relatos del sepulcro vacío, y en la sección de textos alusivos refiere de la siguiente manera:

son otros textos que merecen ser tenidos en cuenta. Su significación reside justamente, en que a pesar de hablar del destino de Jesús después de su muerte o de aludir a él, no acuden por lo menos de manera explícita a la categoría de resurrección. No hablan, en efecto, ni de sepulcro vacío ni de apariciones, sino que se centran en la expectación de la pronta venida del Hijo del Hombre, ahora glorificado en el cielo ${ }^{48}$.

Muy seguramente no ignoraban la muerte y resurrección, pero ponían su énfasis en lo ya dicho. Es más, apoyado en Schillebeeckx, dice Queiruga: "el esquema abajamiento/exaltación a primera vista no necesita necesariamente conocer (ni negar) la resurrección"49. A ello debemos agregar la condición del documento $\mathrm{Q}$, reconocido a partir de la composición de los evangelios Mateo y Lucas, en el cual no existe un relato ni una fórmula de la muerte y la resurrección. Peel piensa que "su Cristología -del documento Q- presume el modelo", y además:

El documento preservó las palabras del Vocero de la Sabiduría, por definición en este período, (se trataba) del justo perseguido y vindicado, quien estuvo en la línea de Abel y de los profetas (Mt 23, 34-35; Lc 11, 49-51). En algún punto en la historia del documento Jesús fue también identificado como el hijo del hombre cuyo futuro status judicial, sería el resultado de la función exaltativa de su resurrección. Así la autoridad de los logía fue tratado retrospectivamente para uno que fue crucificado por su misión profética y prospectivamente para ser exaltado Uno que juzgaría o atestiguaría sobre aquellos que lo confesaran o lo negaran (Mt 10, 32; Lc 12, 8) $)^{50}$.

Debe tenerse en cuenta que, entonces, no hay un solo esquema. El escrito más conocido como el primer relato original de la pa-

Ibíd., 52

49 Igualmente con Crossan, se llega a la conclusión de que en tradiciones tan importantes como la fuente Q, el Evangelio de Tomás, la Didaké, "no muestran evidencia de conocer ninguna narración de la pasión-resurrección", de manera similar, y a diferencia del Evangelio de Pedro y de 1Co15, 3s, "la tradición premarcana no conoce ninguna tradición del resucitado". Ibíd., 53; y n. 33.

Malcolm Peel, op. cit., 688. 
sión y muerte fue Marcos. Lo que comenzó en pequeñas unidades orales y escritas, llegó a transformarse en la estructura de pasiónmuerte-resurrección a partir de los hechos desnudos y brutales de la crucifixión. Los modelos para una tal elaboración fueron bíblicos y no necesariamente históricos. El esquema útil para tal fin no era el esquema pasión-muerte-resurrección-apariciones propio de 1 Co 15, 1-4, ni desde el esquema descenso-ascensión según el antiguo himno de Fil 2, 6-11, sino que era el de persecución-vindicación.

El primer esquema ${ }^{51}$ está en el relato de 1Co 15, 1-11. Pablo unió allí elementos que la tradición tenía de manera separada ${ }^{52}$. Al fin y al cabo es una tradición recibida, no creada por el apóstol. La fuente básica en la elaboración de ese testimonio es el Antiguo Testamento: desde los profetas, fundamentalmente el Deuteroisaias en los textos donde aparece el Siervo sufriente (Is 38, 17; 53, 4. 5. 6; Miq 7, 19 el que soporta los pecados de los otros recibe como recompensa la reivindicación). En ese mismo sentido se orientan los textos de $2 \mathrm{Mac}$ 7, 9 (la madre y sus hijos mártires) y el texto de Sab 2, 4-5, donde aún basado en Is 53, se plantea la recompensa ya no antes de la muerte sino después de ella. El modelo 'persecución-vindicación' ${ }^{\prime 53}$ traducido como 'muerte-resurrección', es el que Pablo reconoce y manifiesta en el escrito más antiguo de 1Co 15.

El segundo esquema corresponde al primer modelo narrativo de Mc 8-16. Allí se hace conexión con textos proféticos ${ }^{54}$, pero sobre todo con Sab 2-5 desde el paradigma de la reivindicación al estilo

51 Hernán Cardona, op. cit., 63-69.

52 Juan Caba, op. cit., 87. San Pablo ha unido lo que podían ser dos eventos, muerte-resurrección, a partir del término "según las escrituras". Ibíd, 92.93.100.

53 Ese mismo modelo prevalece bíblicamente: Fil 2, 6-11 y otras confesiones de fe previas a Pablo: 1 Co 11, 23; Rom 1, 3; 3, 25; 4, 25; Ga 1, 4; Tob 1, 10-22; José, hijo de Jacob Gn 39, 42; los personajes de Dan 3; Daniel en el foso de los leones Dn 6, 16-28; Susana, Daniel 13; todos los judíos en Est 3. Los protagonistas de estas historias corren grave peligro de muerte, y después de invocar a Dios, logran salvar sus vidas. Hernán Cardona, op. cit., 68.

54 En palabras de Bultmann: “...los escritores neotestamentarios no han conseguido nuevos conocimientos desde los textos veterotestamentarios, sino desde ellos extraen, o sea en ellos leen, lo que ellos ya sabían". César Carbullanca 49, "Los signos de los tiempos: apuntes sobre el sentido teológico de la historia en el evangelio de Marcos", Teología y Vida 49, Vol. xLIx (2008): 652. www.scielo.cl/ scielo.php?pid=S0049-34492008000300005\&script=sci_arttext\&tlng $=$ e. 
del Siervo sufriente: su vindicación se realiza después de la muerte y no antes de ella ${ }^{55}$; este esquema adquirió un perfil netamente individual, sin que por ello descartemos otros esquemas que son de carácter comunitario.

El tercer esquema, de carácter comunitario, sin excluir el individual, es el que se encuentra dentro del evangelio de Pedro: se trata del Evangelio de la cruz. Describamos brevemente estos dos testimonios literarios antiguos:

se debe considerar a otro grupo de escritos apócrifos que relatan la pasión, la muerte y la resurrección de Cristo. Uno de los textos existentes más importantes sobre la obra redentora del Señor es el Evangelio de Pedro (...) Se trata de la última fase de la vida terrena de Jesús y de su exaltación gloriosa. El autor de este evangelio interpreta estos hechos a la luz del Antiguo Testamento. Este texto contiene probablemente tradiciones paralelas a los evangelios canónicos y responde, con mucha verosimilitud, a una tradición oral repetida en la liturgia y en la predicación y reposa sobre una memoria colectiva propia de un cristianismo popular. Es un escrito antiguo que, partiendo de tradiciones más arcaicas, fue redactado en el siglo II. Representa la enseñanza y la autoridad del apóstol Pedro (...) En todo caso, este evangelio no presenta características docetas y, como los evangelios de la Infancia, no contiene afirmaciones heterodoxas. De hecho, durante largo tiempo, estos dos tipos de evangelios fueron objeto de una gran devoción ${ }^{56}$.

Dentro del evangelio de Pedro, se encuentra el llamado "Evangelio de la Cruz", fuente común a los relatos de la pasión de los sinópticos. El segmento 8, 28-11, 49 sería el relato más antiguo de la resurrección de Jesús, que dataría de la segunda mitad del s. II,

En los textos antiguos la vindicación antes de la muerte está más extendida, por ser propia de relatos, narraciones e historias desde los inicios de Israel. Es el libro de la Sabiduría el que cambia la recompensa pre-mortem que había en Is 52-53, y empieza a dar cuenta de una vindicación postmortem. Contribuyen a esto el contacto con los persas, con los griegos y la rebelión macabea. Pero una reivindicación no es mejor que la otra, ambas tienen sus raíces en el Antiguo Testamento. Ibíd. Pius-Ramón Tragán, Los evangelios apócrifos: origen-carácter-valor (Navarra: Editorial Verbo Divino, 2008); cf. Hernán Cardona, op. cit., 82-97; Una palabra autorizada, como la de R. Brown, reconoce que "...Hay también referencias de la pasión en "evangelios apócrifos" como EvPe y el Evangelio de Nicodemo (Hechos de Pilato); pero (...) tales escritos son de época más tardía y no añaden ni un solo dato histórico a lo que sabemos de la pasión por los evangelios canónicos. Sirven, eso sí, como importantes testimonios de cómo era percibida y narrada la pasión en un período posterior". R. E. Brown, La muerte del Mesías, desde Getsemaní hasta el sepulcro, Tomo I (Navarra: Verbo Divino, 2005), 42. n. 110. Véase una completa exposición de este apócrifo, en el Tomo II de esta misma obra, donde además se confirma la condición no doceta del mismo. Ibíd., 1547-1582. 
pero se basa en un relato antiguo de la Pasión y de la Resurrección independiente de los sinópticos ${ }^{57}$.

Como escrito, este Evangelio de la Cruz, se supone compuesto hacia el s. II d.C. y tiene estrechos paralelos con los evangelios sinópticos. En aquel escrito Jesús aparece como el primer resucitado y él sale a la cabeza de la resurrección grupal. Después de la muerte el primer y segundo día identifican la resurrección individual, pero el tercer día designa la resurrección comunitaria y en el relato Jesús sale del sepulcro sostenido por dos ángeles y seguido por una procesión organizada en forma de cruz. El único asesinado (en la cruz) no fue Jesús, tampoco el único resucitado.

Recapitulemos: en esta misma línea de desarrollo se halla la composición paulina de 1Co 15: la resurrección no es un privilegio solo de Jesús (como Elías arrebatado al cielo). La resurrección de Jesús tiene lugar exclusivamente dentro de la resurrección general, "si no hay resurrección de muertos tampoco Cristo resucitó" (1Co 15, 13).

Las posibilidades de interpretación que ofrecen las fuentes permiten concluir que la narración de la pasión-muerte-resurrección no fue una historia recordada sino una profecía historiada, es decir, el cumplimiento de las escrituras alcanzaba el máximo de su expresión porque no se hacía historia con los recuerdos de lo sucedido, sino teniendo como referencia las Escrituras Sagradas.

Pero eso no significa que la historia y los hechos acaecidos, no tanto en los «tres días» de la condena histórica, la crucifixión y la resurrección de Jesús, sino en los acontecimientos del s. I, no fueran también parte del ambiente socio-histórico que perfiló la experiencia teológica: la persecución de Agripa I contra los primeros cristianos, la muerte de Esteban (entre el 34-38 d.C), la muerte de Santiago, hermano de Juan (en el 41 d.C), y la de Santiago, hermano de Jesús (en el a. 62), ocurrieron todas bajo la dinastía sacerdotal de la casa de Anás (asociado como sabemos a la muerte de Jesús), dinastía que 
recuperó el poder a la muerte de Calígula, y se vio privilegiada por el nuevo emperador Claudio.

Pero eso, el modelo persecución-vindicación se impuso, en los acontecimientos de ese mismo siglo:

- Sucedió con Flavio Josefo, amenazado por Vespasiano y luego reconocido como profeta pro-imperial.

- También con Agripa I, hecho prisionero en Roma, y seis meses después su verdugo el emperador Tiberio, murió.

- Con los judíos de Egipto, amenazados por el gobernador Flaccus, removido pocos meses después de su cargo.

- Con los judíos de Palestina amenazados de muerte por Calígula, y quien deseaba ver una estatua suya en el templo de Jerusalén; a los pocos meses murió asesinado.

Este modelo se manifiesta en el evangelio de la cruz: lo aplicaron los judíos a Agripa I y a los judíos perseguidos entre los años 37-44, y posteriormente los cristianos de Jerusalén, en el Evangelio de la cruz, usaron de nuevo el modelo para hacer su relato sobre Jesús (43-44 d.C.) apenas sucedió la muerte de Agripa I.

\subsection{En consecuencia}

Nos surge, ahora, una inquietud que ya hemos dilucidado al hacer lectura de la segunda parte. En aquella, se nos refería la "significación secundaria" de la muerte de Jesús.

Aquí, de nuevo, hallamos elementos para dialogar sobre aquella posición. Dice Pannenberg:

la fundación cristiano-primitiva de la fe en Jesús como el Cristo de Dios, en su exaltación e identificación con el Hijo del Hombre, va tan esencialmente unida con estos elementos de la esperanza apocalíptica del fin, que resulta necesario afirmar: si nosotros en modo alguno pudiéramos participar en la esperanza apocalíptica, entonces también la fe cristianoprimitiva en Cristo nos sería imposible (...) Hay que darse cuenta, por tanto, de que cuando se discute acerca de la verdad de la espera apoca- 
líptica en un juicio futuro y en una resurrección de los muertos, se trata inmediatamente del fundamento de la fe cristiana ${ }^{58}$.

Pannenberg menciona la identificación con el Hijo del Hombre y la exaltación, la espera apocalíptica de un juicio futuro y la resurrección de los muertos, pero no menciona la condición de la muerte (por crucifixión). Aquellos cuatro elementos, ¿̇son el fundamento de la fe cristiana?, ¿Es la crucifixión un elemento que pueda considerarse independiente, para mantener separadas la cristología ascendente y descendente, afirmando metodológicamente la primera para ignorar u obviar la segunda? ${ }^{59}$

En 1Co 15, 1s. sobresalen los elementos esenciales que distingue la fe de la comunidad primitiva en una formulación considerada la más antigua ${ }^{60}$. De hecho es el mismo Pannenberg quien reconoce que la fórmula más antigua, previa a la que tenemos en el texto canónico, incluía la muerte "por nuestros pecados según las escrituras" y la visión por parte de Cefas. No se mencionaba la resurrección, que se agregó más tarde. Sin embargo, Pannenberg es radical, cuando afirma: "Desde el momento en que la intención de estas fórmulas tendía originariamente a legitimar a un individuo o a un grupo, bajo el supuesto de la realidad de la resurrección de Jesús, la misión cristiana, y en todo caso Pablo, ha compilado todas estas fórmulas en el texto en cuestión, con el fin de demostrar su presupuesto: la resurrección de Jesús"61. Nos preguntamos: si es Pablo el que ha unido una fórmula más antigua con otra salida de su propio cuño, entonces, de toda la fórmula żlo único que quiere hacer relevante

58 Wolfhart Pannenberg, Fundamentos de cristología, op. cit., 102.

59 Aunque el autor sostiene que hasta ahora no se ha solventado de ninguna manera la cuestión acerca de la verdad de la espera apocalíptica, sin embargo la consideración respecto a la muerte en cruz, no se ha explorado. Tal vez sea una limitante, impuesta por la lectura cristológica descendente, detallar los aspectos teológicos de la cruz como signos del fin del mundo (oscuridad sobre la tierra, terremoto). Estos son los que hacen que la perspectiva apocalíptica de fin del mundo se haga presente antes de la resurrección. Pero, insistimos, esos son elementos, desde el punto de vista de Pannenberg de carácter ascendente, y tendríamos que leer el acontecimiento de la cruz sin esas características. Al quitárselas, deja de ser un evento teológico-escatológico -es un crucificado más-, y solo nos queda la resurrección que es propiamente apocalíptica. Este, hasta ahora nos parece sea el procedimiento de Pannenberg y por esto, se puede considerar que la apocalíptica queda recortada. Ibíd., 103.

60 Ibíd., 112.

61 Ibíd., 113. 
es la resurrección? Será interesante saber si las fórmulas iniciales pretendían mencionar sin detalles la muerte a causa de su impacto ${ }^{62}$. Los detalles podrían ser más tardíos (el resucitado es el crucificado).

Lo que sí es evidente en la obra Teología sistemática es que la muerte por sí misma adquiría un significado atribuido a Jesús, incluso independiente del acontecimiento de la Resurrección (como la muerte del justo perseguido), y se podría incluso afirmar, a causa de una tradición propia que hablaba de una muerte, y esta con sentido expiatorio; y, así mismo, el acontecimiento resurrección tendría significado propio con una tradición propia, no necesario de manera exclusiva para establecer una explicación a la muerte en cruz (como la resurrección de los muertos y estos no a partir de una muerte violenta). Pero sí se puede afirmar que ambas tradiciones confluyeron y adquirieron mayor significado en el acontecimiento de muerte y resurrección de Jesucristo ${ }^{63}$.

\section{Sobre la apocalíptica}

Hay otro punto que es menester observar. Pannenberg dice: "si las concepciones apocalípticas sobre el fin del mundo, pudieran desprenderse de muchos de sus detalles, entonces sus elementos básicos, la esperanza de una resurrección de los muertos en relación con el fin del mundo y el juicio final, podrían seguir siendo válidas también para nosotros" ${ }^{\prime 64}$.

Después de haber hecho uso de algunos textos apócrifos ${ }^{65}$ será difícil renunciar a los detalles literarios que distinguen al género apo-

En 1 Co 15, 1s Pablo menciona la muerte sin hacer referencia a la crucifixión, pero eso no implica que Pablo la desconozca (cfr. 1Co 1, 23). En el contexto del cap. 15, se desarrolla el problema de la muerte común a todo ser humano, como lo está sometido también Jesús. Al emplear el tiempo aoristo para decir "murió", se está situando el suceso en el pasado. Quiso Pablo, por este medio, enfatizar que se trata de una muerte real y no de una muerte aparente, no fue enterrado vivo, de tal manera que, al recuperar sus fuerzas pudiera salir del sepulcro. José Caba, op. cit., 92. Wolfhart Pannenberg, Teología sistemática, op. cit., 373.

64 Ibíd., 102.

65 Las referencias intertestamentarias son necesarias: si Pannenberg da por incluida y aceptada una tradición como la caída de los ángeles, la cual hunde sus raíces en textos extrabíblicos, entonces es posible aceptar, también, una amplitud de tradiciones para enfocar la resurrección. Wolfhart Pannenberg, Fundamentos de cristología, 80; n. 36-37. 
calíptico. Pannenberg, si se nos permite tenerlo en cuenta, recurre a pocos textos canónicos en su texto Fundamentos, y a una cantidad más o menos considerable de textos extracanónicos, para fundamentar esta tercera parte del artículo en estudio. Lo canónico y lo extracanónico se van amalgamando hasta ponerse al servicio de la Revelación.

Se puede apreciar la literatura apocalíptica ${ }^{66}$ precisamente por sus detalles, pues la literatura apocalíptica se caracteriza literariamente hablando, por ese montaje necesario de detalles, puesto que los elementos «indispensables» (el templo, el sacerdocio, la monarquía) sobre los cuales se proveía la salvación, ya no existen. Lo que debe hacer la apocalíptica es resignarse a saber que la salvación no depende ya de los esfuerzos humanos, y todo proviene del Señor. Por eso el lenguaje es nuevo: templo celeste, el énfasis en la angelología, el guerrero divino, la visión, la revelación de los secretos, Dios y su arma de fuego, "el drama cósmico ya no está unido a las realidades históricas", el pueblo se transforma en ejército que se torna victorioso ${ }^{67}$.

Pannenberg le dice «sí» a la apocalíptica, parece convertirla en su fuente y la base de sus afirmaciones sobre la resurrección, pero

66 "Las trasformaciones políticas fueron acompañadas de un cambio radical en las ideas sobre la realización de la salvación. Este cambio está asociado con el nombre de la apocalíptica, la cual debe contemplarse en relación íntima con los jasidim. Nos permitirán comprenderla los escritos apocalípticos, entre los que hay que contar el libro de Daniel y el de Henoc. Si hasta ahora se había contemplado el dominio de Dios en el juicio y la salvación como un acontecimiento exclusivamente intramundano, ahora se miraba hacia el fin de la historia. En ese final de la historia se manifestaría Dios, llamaría a los muertos para que salieran de sus sepulcros y los despertaría a nueva vida y celebraría un juicio individual en el que se juzgaría según las obras". Joaquín Gnilka, op. cit., 69; si la descripción apocalíptica de los acontecimientos escatológicos pierde importancia, entonces no es necesaria la tradición judía. Cf. Wolfhart Pannenberg, Fundamentos de cristología, 77; prólogo, 21. Álvaro Cadavid, op. cit., 530.

67 "Hay que combinar, por tanto, forma literaria y contenido, y tener en cuenta estos cuatro planos: 1) Características del lenguaje apocalíptico: repetitivo, largos discursos; predominio de cifras y listas, simbolismo de los números; aves, bestias, dragones simbólicos. 2) Características estructurales: no se menciona el autor de la obra; el discurso se pone en boca de un personaje de la Antigüedad (Noé, Lamec, Henoc) o, al menos, de tiempos bíblicos exílicos (Baruc, Daniel, Esdras); el héroe es transportado al cielo, donde se le muestran misterios que se le han de explicar después; el intérprete es con frecuencia un ángel; los ángeles son piezas básicas en la mecánica de muchos apocalipsis; el visionario queda perturbado, se desvanece, cae sobre su rostro, etc. 3) Contenido narrativo: a menudo aparece un hilo narrativo nuevo de largas secuencias históricas, generalmente en formas simbólicas crípticas, en el que animales en lucha simbolizan las lizas de los hombres; hay descripciones de los cielos, vientos, de extrañas montañas, del árbol de la vida. 4) Doctrinas que conciernen a la resurrección, la proximidad del nuevo eón, la gran crisis que se cierne sobre la historia del mundo". Alejandro Diez Macho, Introducción General a los Apócrifos del Antiguo Testamento (Madrid: Cristiandad, 1984), 46; cf. Fréderic Manns, Il Giudaismo. Ambiente e memoria del Nuovo Testamento (Bologna: Ed. Dehoniane, 1995), 191-201. 
al tenerla en sus manos, żestará intentando cambiarle su apariencia, para poder llegar a un "estrato histórico"68 de la misma, donde sus detalles ya no sean necesarios? Uno de los problemas en los que ha caído la interpretación de la apocalíptica, está precisamente en el intentar darle una identidad clara y específica a sus elementos y sus símbolos. Y si para llegar a ello se recurre a vaciarla de sus detalles, puede correrse el peligro que quede muda, porque hablar es precisamente a través de sus detalles. Algunas interpretaciones tomaron símbolos y personificaciones de la literatura apocalíptica, dijeron de qué y de quién se trataba, y de esta manera la apocalíptica dejó de ser escatológica, es decir, el respectivo escrito interpretado, aislado de la Revelación, ya no era una teología sobre el fin del mundo. ¿Quitar los detalles, no llevaría a un peligro similar?, ¿cómo puede desprenderse de sus detalles "la concepción apocalíptica sobre el fin del mundo", cuando la apocalíptica es en sí misma "fin del mundo"?

Hay dos medios que pueden ser contradictorios si se combinan el uno con el otro: no es posible usar la apocalíptica -con los elementos que la hacen característica-y al mismo tiempo pretender hacer una cristología desde abajo que no se compromete con los textos interpretados, sino solo con los hechos en sí, es decir, arriesgándose a interpretar acontecimientos sin teología ${ }^{69}$ y una apocalíptica desnuda de su lenguaje propio. Una apocalíptica vacía de su contenido, no propicia una coherente lectura de los acontecimientos -entre ellos la resurrección-. Entonces, si se quiere hacer una cristología ascendente, se frustrará tal intento porque la apocalíptica, en sí misma, es descendente ${ }^{70}$.

Esto es lo que clásicamente se ha hecho con el método histórico crítico, no porque el método sea malo en sí mismo, sino porque se pensó que se podía aplicar de la misma manera a todos los textos bíblicos. No es igual la exégesis de los evangelios sinópticos que la exégesis que se haga con un texto apocalíptico.

69 Esa posición no es compartida por el mismo P. quien intentando corregir a Althaus, dice: "La cristiandad primitiva no hizo esta distinción entre los hechos y su significado, sino más bien para ella el acontecimiento y el significado de la resurrección de Jesús iban estrechamente unidos". Wolfhart Pannenberg, Fundamentos de cristología, op. cit., 136.

70 Cf. la crítica del prólogo de la misma obra de Pannenberg que estamos estudiando. Ibíd., $15 \S 4$. 
Esa es la posición que toma el mismo Pannenberg y lo reconoce, ya adentrados en el tratado IV de su exposición, cuando sostiene, refiriéndose a las apariciones del Resucitado:

Con respecto a ello, se ha de hablar en un lenguaje simbólico, como los mismos discípulos. Pero esto no ha de representar para nosotros, como tampoco lo representaba para ellos, un obstáculo para comprender la marcha del acontecimiento con ayuda de lo indicado con este lenguaje, desde el momento en que las demás posibilidades de explicación aparecen como insostenibles (...) lo que sólo es expresable en el lenguaje de la esperanza escatológica hay que afirmarlo como un suceso históricamente acaecido ${ }^{71}$.

Esta consideración confirma, por lo tanto, la valoración que aprecia la apocalíptica en y por sus detalles ${ }^{72}$. Son los secretos y los símbolos los medios que distinguen este género literario.

\subsection{De los apócrifos a los evangelios}

Vale la pena destacar que la Escritura y la historia no solo se unieron, sino que eran elementos inseparables en la comunidad. Esa inseparabilidad se realiza en la visualización de la muerte y la resurrección de Jesús a la luz de las profecías del Antiguo Testamento. El término que identifica el cumplimiento de las Escrituras, será deî ("es necesario que") y, su contenido semántico responde a una necesidad apocalíptica, es decir, "es Dios quien ha determinado la historia y conoce todo antes de que ocurra, esta vinculación a la voluntad personal de YHWH se grafica en el recurso al tema del «libro o las tablas de los cielos», o del «estar escrito» en diversos

71 Ibíd., 122.

72 Entre los principios exegéticos de la apocalíptica, son importantes: 1. El judaísmo clásico únicamente admitía la revelación de la ley hecha a Moisés y pensaba que no había otra revelación. Los apocalípticos, además de tal revelación, admitían la de las siete tablas escondidas en el cielo que habían sido reveladas a Moisés, patriarcas y profetas o al Maestro Justo de Qumrán. La revelación, pues, estaba recopilada sólo en parte, ya que sólo se había consignado en la Torá de Moisés, la de dos de las tablas. Quedaban muchos otros secretos que, revelados a los antiguos, no habían sido conservados por escrito ni en la tradición, por lo que debían ser revelados de nuevo. El principio que regía la exégesis rabínica: "nada ha quedado en el cielo», no valía para los apocalípticos. La revelación continuaba abierta. 2. Los secretos de las siete tablas son revelados a los autores apocalípticos, y de ahí deriva el nombre de su literatura, ya que el término griego «apocalipsis» significa revelación. Alejandro Diez Macho, op. cit., 89. 
textos relacionados a corrientes apocalípticas de la época surge la referencia a este tema"73.

Tres aspectos surgen de las fuentes enóquicas y qumránicas ${ }^{74}$ : el carácter escrito de la voluntad divina, ya no la visión o el sueño: el texto de la Escritura se convierte en el mediador para descubrir la voluntad de Dios; los hechos anunciados son inamovibles, y estos mismos hechos se refieren al período de los últimos días que la comunidad cree vivir, pues, cada época está inscrita en las tablas celestiales, y la interpretación de estas parte de la convicción de vivir los tiempos escatológicos ${ }^{75}$. Entre los apócrifos sobresale el Testamento de los doce profetas, donde los sueños, las visiones y la Escritura, poseen carácter de revelación divina y su interpretación se realiza desde la convicción de vivir los últimos días.

Esta misma idea (a partir de los términos deî y gégraptai) pasa a los evangelios y en especial a Marcos, quien hace uso del deî escatológico, subrayado antes por la apocalíptica judía. La fórmula como está escrito, no se entiende de manera jurídica, sino escatológicamente. "Jesús remite a los padecimientos futuros del futuro Hijo del hombre como profetizados en la Escritura, no como prueba de autoridad, no para "colorear» (apocalípticamente), sino como partícipe de un modo de creer la última etapa de la historia que ella misma vive, la Escritura es entendida como profecía que se cumple en la presente generación de la comunidad"76.

La citación específica de Mal 3, 23, sometida a observación bajo el Texto masorético (TM), la Septuaginta (LXx) y el Targum, y tal como es aplicada por Mc 9, 12-13, permiten concluir, que "no se está refiriendo más a Elías, sino al Hijo del hombre, ni tampoco a un

Tanto la literatura Enóquica, como los textos de Qumram identifican aquella necesidad, no solo como prognosis de Dios, sino además como «la Palabra que viene» comprendida como acontecimiento histórico-escatológico. César Carbullanca, op. cit., 655-658. 
escatológico trabajo de restauración sino al sufrimiento y muerte"77. Bajo este procedimiento lo escatológico, se transforma en cristológico.

\section{Cuestiones para una conclusión abierta}

Nuestra primera parte intentaba hacer conciencia sobre la distancia que nos separa de Pannenberg y su tiempo. Por ello, este escrito se detiene ampliamente en la actual situación de la cristología, para poder leer a Pannenberg con la perspectiva y el alcance de la ciencia bíblica presente y de los avances con los cuales se ha enriquecido la investigación. Como hemos visto, Pannenberg, y con él su obra Fundamentos de cristología, podrían situarse, entonces, en la "Tercera búsqueda" del Jesús histórico y, por lo tanto, adelantaba una reflexión que no tenía un desarrollo pleno y que en algunos de sus puntos llegaría a ser revisada por él mismo.

Y ya que nos hemos aproximado parcialmente a la obra de Pannenberg, conviene escuchar el parecer de lectores y críticos que conocen su trayecto teológico: le reclaman su excesiva historicidad, por ello, se opaca la fe; la historicidad de la resurrección no puede agotar el misterio, no se puede ignorar la necesidad de un lenguaje metafórico para una materia de tal envergadura como la resurrección.

Pero Pannenberg también plantea sus aclaraciones: cuando una propuesta tiene novedad es posible desfigurarla, los acontecimientos tienen sentido en sí mismos y no dependen del significado que les demos, y aquellos dependen del contexto con sus respectivas conexiones para ser comprendidos solo desde la anticipación. En esta labor se ha querido conocer cómo se llega a ese motivo anticipador que se vuelve criterio de verdad para la humanidad y la historia.

Ibíd., 668. 671-672. Marcos usa la expresión deî para referirse a hechos históricos concretos como el destino del Hijo del hombre $(8,31)$, la venida de Elías $(9,11)$, los signos del fin $(13,7)$, la predicación del evangelio $(13,10)$, la profanación del templo $(13,14)$. Estos acontecimientos pertenecen al período escatológico y están ligados a la muerte de los servidores de Dios. 
Teniendo en cuenta el anterior criterio, hemos valorado la articulación del pensamiento pannenberiano al tener en cuenta la obra Teología sistemática en la que hay revisiones, o, por lo menos, Pannenberg sale al paso de posibles malas interpretaciones de su obra Fundamentos de cristología.

En la segunda parte hemos dado inicio a nuestra reflexión problematizando la consideración de la muerte de Jesús como algo secundario, según la opinión de Pannenberg, posiblemente nuestro autor no pretende una separación entre el evento Cristo, sus hechos y palabras y la interpretación de la comunidad, pero se pierde el sentido de lo que significa "el cumplimiento de las Escrituras". En tal sentido no se afirma con insistencia la condición de un canon abierto, al menos por lo que respecta a los escritos anteriores al 70 d.C. (destrucción del templo) o al 90 d.C. (Concilio de Yamnia, y definición del canon judío). Tradición y canonicidad reclaman aquí su lugar.

Es en esa misma línea, de un canon abierto concebido de esa manera por el judaísmo de los dos primeros siglos a.C. y los dos siglos posteriores enmarcados en una dimensión apocalíptica, como hemos intentado responder a la cuestión de la resurrección, respaldada anticipadamente no solo por los textos que pudieran referirla con el solo deseo de responder a la inquietud de un mas allá, sino y sobre todo, como respuesta a una condición de persecución y de martirio. Confluyen en esa lectura los perseguidos en los textos canónicos, deuterocanónicos, pseudoepigráficos, la categoría sociológica de la Estigmatización. Por eso inquietan las palabras que Pannenberg nos dirige respecto a una resurrección más atestiguada en la tradición, y de manera contraria para la crucifixión:

Con respecto a la resurrección de Jesús hemos visto que se trataba de un acontecimiento cuya formulación era totalmente clara dentro del contexto tradicional judío y en relación con la vida prepascual de Jesús. Por lo que se refiere a su crucifixión, sin embargo es distinto. Precisamente a partir de la resurrección tuvo que plantearse la pregunta sobre por qué Jesús debió seguir el proceso de la pasión hasta la cruz, si luego Dios con la 
resurrección de entre los muertos, reconoció la pretensión inusitada con la que Jesús se había presentado ${ }^{78}$.

Sean enfáticas las siguientes palabras y conclusivas para nuestra búsqueda:

Las creencias judías en la resurrección, la inmortalidad y la vida eterna son presupuestas a través de todo el NT, y las antiguas formulaciones cristianas también reflejan la variedad del judaísmo, y esto pertenece a las funciones, tiempo objetivo y modo de la recompensa postmortem. El mayor factor que transforma estas creencias, sin embargo, es la convicción universal de la Iglesia que Dios ha comenzado su proceso escatológico a través de hacer resurgir al crucificado Jesús de la muerte. Cada escrito del NT presume la resurrección de Jesús, y el tópico de la recompensa postmortem es raramente tratada sin referencia o alusión a la resurrección. La resurrección de Jesús es comprendida desde dos perspectivas: primera, se trata de la vindicación de Dios a favor del perseguido Jesús. Esto tiene sentido con la humillación, la tragedia y el escándalo de la crucifixión; y segunda, la resurrección de Jesús tiene más amplias implicaciones, como un acto de salvación por la humanidad y el cosmos. Esto facilita la exaltación de Jesús como Señor y Juez, y las promesas de resurrección y vida eterna para los creyentes ${ }^{79}$.

Dentro de esta segunda parte hemos querido aproximarnos a datos que nos permitiesen confirmar que la herencia judeo-cristiana no se limita al inicio de la literatura escrita neotestamentaria de los años 50-52 d.C. La primera generación de cristianos no estuvo vacía de contenido y de procesos de fe. Si Pannenberg hace mención de la función del Espíritu Santo en la comunidad, entonces no puede dejarse de lado que la comunidad tenía procesos y progresos teológicos en el camino de su fe.

Por lo tanto, como hemos visto, es necesario conocer otros esquemas o modelos que la primitiva comunidad pudo experimentar para transmitir la pasión-muerte-resurrección. Lo confirman, además, sus palabras en la séptima parte de su libro Fundamentos de cristología (La muerte de Jesús en cruz como castigo representativo):

78 Wolfhart Pannenberg, Fundamentos de cristología, op. cit., 305.

79 Malcolm Peel, op. cit., 688. 
Desde el momento en que la resurrección de Jesús no se concibió en relación con una crucifixión, sino que se relacionó directamente con la pretensión prepascual de poder y autoridad por parte de Jesús en cuanto era su confirmación divina, la crucifixión de Jesús apareció desde un principio para el cristianismo primitivo a la luz de su resurrección ${ }^{80}$.

Como se ha reiterado compendiando mayor información a partir de las dos obras de Pannenberg, aquí motivo de estudio, aunque la crucifixión quede subordinada a la resurrección, ambas dimensiones quedan validadas por ser tradiciones que podrían contar cada una por sí misma, con un significado propio pero uniéndose en la figura del Crucificado y Resucitado.

En la misma séptima parte de su libro y respondiendo a la cuestión de Las interpretaciones más antiguas de la muerte de Jesús y su problemática, Pannenberg rechaza la interpretación que Pablo -y tras él la comunidad judeocristiana primitiva-, hace de la aplicación de Dt 21, 23 a Jesús en Gal 3, 13. Nuestra inquietud es: ¿Pannenberg rechaza los métodos de interpretación que la comunidad judeocristiana primitiva posee para acercarse a su propio patrimonio literario? Esos métodos, ¿̇solo son válidos para quienes consideraron que "todas las frases del Antiguo Testamento eran una autoridad irrefutable e intemporalmente válida y desgajadas además de un modo totalmente atomístico y sin relación alguna con el contexto" ${ }^{181}$, pero no son válidos para nosotros? Nos queda el desafío de conocer en la amplitud de su obra, de qué manera tiende Pannenberg a dilucidar esta circunstancia que aparece propiamente en su obra Fundamentos de cristología.

Sirva esta opinión de Dibelius para orientar el diálogo: él decía que ahí donde fallaron los recuerdos de los testigos oculares, se ayudó a la elaboración del texto con citaciones veterotestamentarias de las Escrituras, especialmente en los textos de la pasión. Él mismo se dio a la tarea de reformular su posición: "Dibelius valora el rol que cumplen los testigos oculares y sostiene que este relato es más 
que un informe protocolar; según su opinión la historia de la pasión fue narrada como un testimonio con ayuda del Antiguo Testamento, como cumplimiento de las profecías"82.

Posiblemente pueda aceptarse una subordinación de la cruz a la resurrección, pero se volvería indispensable contar con las tradiciones que con anterioridad perfilaron ambos aspectos del evento único pasión-resurrección porque el evento y su teología respectiva se unen hasta que lo segundo determina lo primero. Así lo describe Cardona en su estudio conclusivo:

La búsqueda de las «Escrituras» se alargó después del esquema Pasión,
Muerte y Resurrección hasta hacerse historia. Y aquí termina de ordina-
rio la aproximación canónica. Pero desde el interés literario la búsqueda
continuó en los textos cristianos compuestos después de los evangelios
canónicos; desde ese momento la tipología, la prueba y la profecía llegan
a ser más y más determinantes como argumento. Ya en esta época casi
todos los salmos fueron referidos de forma exclusiva y profética solo a
Jesús. ¿̇erá necesario e inevitable para esta historia vista desde los sal-
mos sustentar que todo sucedió así? Lo expuesto demuestra la existencia
de la exégesis antes de la historia, de una exégesis sin historia, y de la
exégesis en contra de la historia ${ }^{83}$.

En la tercera parte hemos ilustrado breve y suficientemente los diversos aspectos de la apocalíptica judía a partir de lo que Pannenberg consideraba como necesario, el vaciar de sus detalles a un género que no puede expresar su teología de otra manera sino a partir de aquellos mismos detalles. Un lenguaje escatológico no es un lenguaje ahistórico.

Para demostrar lo anterior, se ha descrito cómo ciertas expresiones que eran propiedad del lenguaje apocalíptico pasaron a ser apoyo en la construcción del segundo evangelio canónico, y le dieron el matiz escatológico, como corresponde a la tensión del tiempo en el que nació, se anunció y se predicó.

82 César Carbullanca, op. cit., 651.

83 Hernán Cardona, op. cit., 76. 77. 100. 120. 
En la entrevista de M. Fraijó, se le recuerda a Pannenberg la acusación de no tomarse en serio la muerte de Jesús y tras ella que no sea sensible al problema del mal. Pannenberg argumenta que bastaría con saber que su biografía intelectual comienza "entre las cenizas de la II Guerra mundial" ${ }^{84}$.

Por eso afirma de manera explicita: "No había ningún motivo para una teología de la cruz, si a la crucifixión no hubiese seguido la resurrección del crucificado"85. De esta manera vuelve a asegurar que la muerte en cruz es consecuencia de la predicación de Jesús, y sin vacilaciones aclara: "Aunque por caminos distintos a los acostumbrados, soy fiel a la herencia de la tradición, tampoco caigo en la tentación de reducir el mensaje cristiano al tema de la muerte de Jesús" ${ }^{\prime \prime 6}$.

Desde aquí se logra interpretar que Pannenberg se mantiene firme en su posición, y aquello es verdadero. Para llegar a donde ha llegado Pannenberg hemos querido simplemente explorar qué era lo que había en la comunidad cristiana en términos de una teología enrutada por la fuerza de la Tradición, porque no se llega al acontecimiento de la muerte y la resurrección, sino por un camino exegético, donde el acontecimiento histórico, no solo nos llega teologizado, sino que tal teología funcionaba ya en la comunidad antes de los eventos, y esa teologización no pretende borrar la historicidad (de los acontecimientos), sino todo lo contrario, confirmarlos.

Es posible comprender la queja de Pannenberg dentro de su bagaje teológico: “Si solo se ve en la resurrección de Jesús una expresión gráfica del lenguaje cristiano para destacar el significado de la muerte de Jesús, entonces una tal interpretación no comparte la fe de la Iglesia y no debería aparentar que la comparte"87. Este retroceso resulta inaceptable para Pannenberg, pero si la historia resulta iluminada por el evento de la resurrección hacia adelante y

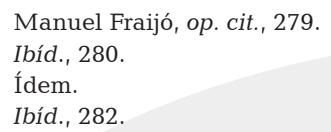


prolépticamente, también lo pasado resulta iluminado, y no sólo eso, es también iluminante.

\section{Bibliografía}

Aguirre, Rafael. «La 'Third Quest' ¿Una nueva investigación?» RCatT 2, Vol. xxxiII (2008). www.raco.cat/index.php/RevistaTeologia/article/viewArticle/130493/0

Brown, Raymond E. La muerte del Mesías, desde Getsemaní hasta el sepulcro. Tomo I-II. Navarra: Verbo Divino, 2005.

Caba, José. Resucitó Cristo, mi esperanza, estudio exegético. Madrid: BAC, 1986.

Cadavid, Álvaro. "La investigación sobre la vida de Jesús". Teología y Vida 43, Vol. XLIII (2002). www.scielo.cl/scielo. php?pid =S0049-34492002000400003\&script $=$ sci_arttext.

Carbullanca, César. "Los signos de los tiempos: apuntes sobre el sentido teológico de la historia en el evangelio de Marcos". Teología y Vida 49, Vol. xuIx (2008). www.scielo.cl/ scielo.php?pid = S0049-34492008000300005\&script $=$ sci arttext\&tlng $=\mathrm{e}$

Cardona, Hernán. Los cristianos del 30 al 50 e.C. Medellín: Universidad Pontificia Bolivariana, 2003.

Diez Macho, Alejandro. Introducción general a los apócrifos del Antiguo Testamento. Madrid: Cristiandad, 1984.

Fraijó, Manuel. "Pannenberg enjuicia su propia teología. Entrevista...", en El sentido de la historia. Introducción al pensamiento de W. Pannenberg. Madrid: Cristiandad, 1986.

Gnilka, Joachim. El evangelio según San Marcos, Vol. II. 4. ${ }^{a}$ Ed. Salamanca: Sígueme, 2001.

. Jesús de Nazaret, mensaje e historia. Barcelona: Herder, 1993. 
Guijarro Oporto, Santiago. Jesús y el comienzo de los evangelios. Navarra: Verbo Divino, 2006.

Manns, Fréderic. Il Giudaismo. Ambiente e memoria del Nuovo Testamento. Bologna: Dehoniane, 1995.

Meier, John P. "Las raíces del problema y la persona", en Un judío marginal, Nueva visión del Jesús histórico. Tomo I. Navarra: Verbo Divino, 1998.

Pannenberg, Wolfhart. "La resurrección de Jesús como fundamento de su unidad con Dios", en Fundamentos de cristología. Salamanca: Sígueme, 1974.

. "La divinidad de Jesucristo", en Teología sistemática. Vol. II. Madrid: UPCO, 1996.

Peel, Malcolm. "Resurrection (Early Judaism and Christianity)", en Anchor Bible. Vol. 5. New York: Doubleday, 1992.

www.verbodivino.es/documentos/PrimerCapituloPDF/2212.pdf.

Theissen, Gerd- Merz Annette. El Jesús histórico: manual. Salamanca: Sígueme, 1999.

Torres Queiruga, Andrés. Repensar la Resurrección. Madrid: Trotta, 2005.

Tragán, Pius-Ramón. "Los evangelios apócrifos: origen-caráctervalor". Navarra: Verbo Divino, 2008.

Zañartu, Sergio. "Reseña de: 'Jesús. Los orígenes históricos del cristianismo desde el año 28 al 48 d.C' de Fernández Eyzaguirre, Samuel". Teología y Vida 1-2, Vol. XLIx, (2008). http:// redalyc.uaemex.mx/redalyc/pdf/322/32214688012.pdf. 